\title{
Positive or negative spirals of online behavior? Exploring reciprocal associations between being the actor and the recipient of prosocial and antisocial behavior online
}

new media \& society

(C) The Author(s) 2018

Reprints and permissions: sagepub.co.uk/journalsPermissions.nav DOI: I0.1 I77/|46|4448|77495|8 journals.sagepub.com/home/nms

\section{Sara Erreygers}

University of Antwerp, Belgium; KU Leuven, Belgium

\section{Heidi Vandebosch}

University of Antwerp, Belgium

\section{Ivana Vranjes}

University of Antwerp, Belgium; KU Leuven, Belgium

\section{Elfi Baillien}

KU Leuven, Belgium

\section{Hans De Witte}

KU Leuven, Belgium; North-West University, South Africa

\begin{abstract}
Bidirectional associations between being cyberbullied and cyberbullying others have been suggested, as well as bidirectional patterns of online prosocial behavior (reciprocity). However, so far, these relations have been studied as population-level associations, and it is not clear whether they also reflect within-person behavioral patterns. Therefore,
\end{abstract}

\section{Corresponding author:}

Sara Erreygers, Department of Communication Studies, University of Antwerp, Sint-Jacobstraat 2-4, Z.109, 2000 Antwerpen, Belgium.

Email: sara.erreygers@uantwerpen.be 
this study aimed to disentangle between-person and within-person processes in online antisocial (cyberbullying) and prosocial behavior over time. Random intercept cross-lagged panel models were used to examine long-term within-person patterns of involvement in cyberbullying and online prosocial behavior. The findings showed no within-person effects between cyberbullying victimization and perpetration over time. In contrast, results did reveal significant within-person autoregressive effects of performing and receiving online prosocial behavior over time, and within-person crosslagged effects between receiving online prosocial behavior and acting prosocially later on. These results indicate long-term positive, reinforcing spirals of prosocial exchanges, but no long-term negative spirals of cyberbullying perpetration and victimization.

\section{Keywords}

Cyberbullying, online behavior, prosocial behavior, random-intercept cross-lagged panel models, reciprocity

\section{Introduction}

In the last decades, digital technologies have created new opportunities for social behavior, which can now also take place online. Accordingly, online forms of social behavior have emerged, such as cyberbullying. A large and growing body of literature has examined cyberbullying and the factors related to it, and a few studies have investigated and confirmed the association between cyberbullying victimization (CBV) and cyberbullying perpetration (CBP) (Ak et al., 2015; Festl et al., 2015; Festl and Quandt, 2016; Kowalski et al., 2014; Schultze-Krumbholz et al., 2015; Vandebosch and Van Cleemput, 2009; Walrave and Heirman, 2011; Wright and Li, 2013). However, questions remain about the causal and temporal direction of the association at the level of the individual (i.e. do cyberbullies become cybervictims, or vice versa?).

The link between performing and experiencing a behavior has not only been shown for antisocial behavior, such as bullying and aggression but also for prosocial behavior, such as in reciprocal helping (Trivers, 1971). Online prosocial behavior has received much less research attention than its counterpart - online antisocial behavior. ${ }^{1}$ Although some studies have examined online prosocial behavior in specific contexts, such as couchsurfing (Lauterbach et al., 2009) and online gaming communities (Nelson and Rademacher, 2009), no previous research has examined associations over time between being a recipient and being an actor of general online prosocial behavior. Moreover, at present, cyberbullying and online prosocial behavior have not been studied simultaneously, although studies on offline social behavior have examined bullying and prosocial behavior together (Menesini and Camodeca, 2008; Warden and Mackinnon, 2003). Therefore, in this study, we aim to shed light on the longitudinal within- and between-person dynamics of online antisocial and prosocial behavior by examining the associations between CBV and CBP on the one hand and receiving and performing online prosocial behavior on the other hand, using random-intercept cross-lagged panel modeling.

In what follows, we first review the literature on CBV and CBP and on prosocial behavior. Then we discuss how the associations between performing and experiencing 
these behaviors have been analyzed so far and what the added value of using randomintercept cross-lagged panel modeling is. This is followed by a detailed discussion of the methods and the results of this study.

\section{$C B V$ and $C B P$}

Cyberbullying is an intentional negative behavior that occurs via electronic technologies (Smith et al., 2008). An extensive body of literature has explored cyberbullying and its associated antecedents and consequents (for a meta-analysis, see Kowalski et al., 2014). Some of these studies have examined the relationship between victimization and perpetration of cyberbullying, and most suggest a positive association (Ak et al., 2015; Festl et al., 2015; Festl and Quandt, 2016; Kowalski et al., 2014; Schultze-Krumbholz et al., 2015; Vandebosch and Van Cleemput, 2009; Walrave and Heirman, 2011; Wright and Li, 2013). Notably, individuals who are both victim and perpetrator of cyberbullying (often called bully-victims or aggressive victims) seem to fare worse psychologically than "pure" cyberbullying victims or bullies (Bayraktar et al., 2014; Sourander et al., 2010; Völlink et al., 2013).

Although there is evidence for a link between CBP and CBV, the dynamics behind this association have not been fully uncovered. One suggested explanation is that cybervictims take revenge or retaliate and turn against the bully (König et al., 2010). Cybervictims may experience anger and frustration, and as some form of maladaptive coping strategy, may turn to cyberbullying as a way to vent their negative feelings.

In addition, when someone cyberbullies others, this may lead to that person becoming a target of cyberbullying him- or herself, resulting in cycles of cyberbullying (Kowalski et al., 2012). Hence, the association between cyberbullying and cybervictimization could be bidirectional. Bidirectionality of aggressive acts is postulated in the General Aggression Model (GAM, Anderson and Bushman, 2002) as one of the mechanisms behind violence. The GAM is a comprehensive framework that integrates the role of social, cognitive, personality, developmental, and biological factors to explain aggression (Allen et al., 2018). According to the GAM, aggression can be understood as a combination of distal and proximate processes. Distal processes involve a combination of biological and persistent environmental processes, which can influence personality through altering knowledge structures, and thereby shape proximate processes (Anderson and Bushman, 2002). Proximate processes operate during specific aggressive episodes in three stages, namely, inputs, routes, and outcomes (Anderson and Bushman, 2002). Person and situation factors serve as inputs which influence appraisal and decision processes (outputs) through present internal state variables (cognition, affect, and arousal). These appraisal and decision processes can guide aggressive or non-aggressive actions, which can in their turn reshape the person and situation inputs, leading to a new cycle of proximate processes (Allen et al., 2018). According to the GAM, "most acts of violence result from a series of conflict-based interactions that involve two (or more) parties trading retaliatory behaviors in an escalating cycle" (Anderson et al., 2008: 463). One person's retaliation provokes a retaliatory reaction from the other, resulting in an escalating cycle of aggression, a so-called violence escalation cycle (Anderson et al., 2008). Applied to cyberbullying, the violence escalation model predicts that a triggering event (e.g. a 
provocation online from person A), that is perceived as intentional, harmful, or unjustified, may elicit an aggressive online response from person B, which in turn provokes a retaliatory reaction from person $\mathrm{A}$, and so on, developing into a reinforcing cycle of cybervictimization and cyberperpetration. However, (cyber)bullying is a special type of aggression, characterized by a power imbalance between the victim and the bully. Therefore, in (cyber)bullying, the likelihood that the victim retaliates against the bully may be smaller, because the bully is (perceived as) more powerful. Nevertheless, this does not preclude that a (cyber)victim would react aggressively toward another person than the original perpetrator (as some form of indirect retaliation). Furthermore, because of the possibility to act anonymously online, retaliation might be easier in cyberbullying than in offline bullying. Also, the online disinhibition effect (Suler, 2004), which describes the lowered restraint people experience in online versus offline communication, may lower the threshold to retaliate online versus offline.

\section{Prosocial behavior: dynamics and online manifestations}

Antisocial behavior, such as cyberbullying, is behavior that harms or lacks consideration for the welfare of other people. Yet, people also often behave in ways that promote others' well-being. Prosocial behavior is voluntary behavior that is aimed to benefit particular others or to promote harmonious relationships (Dovidio et al., 2006; Eisenberg et al., 2006; Van Rijsewijk et al., 2016). Helping, comforting, or sharing resources with others are ways of behaving prosocially.

Cyclic patterns of behavior have not only been investigated in the domain of antisocial behavior; cycles of prosocial behavior have also been reported (Bartlett and De Steno, 2006; Keysar et al., 2008; Stanca, 2009). Chains of positive exchanges between individuals are examined under the umbrella of "reciprocity."2 Two forms of reciprocity have been distinguished: direct and indirect reciprocity (Rankin and Taborsky, 2009; Roberts, 2008). Direct reciprocity entails "paying it back": Returning a favor after having received one. Indirect or generalized reciprocity entails "paying it forward": Doing someone a favor after having received one from someone else or doing a favor to someone who has helped someone else. The existence of both forms of reciprocity has been established in experimental research (Bartlett and De Steno, 2006; Gray et al., 2014; Rankin and Taborsky, 2009). Furthermore, there are some indications that generalized reciprocity also occurs online (Lauterbach et al., 2009; McLure Wasko and Faraj, 2000; Nelson and Rademacher, 2009). Moreover, research on cooperative behavior in the specific context of video game playing has reported that playing violent video games cooperatively may increase later helping and cooperative behavior (Ewoldsen et al., 2012; Greitemeyer and Cox, 2013; Velez et al., 2014).

Two theories may be drawn upon to explain these findings: the theory of bounded generalized reciprocity (Yamagishi et al., 1999) and the reinforcing spirals model (Slater, 2007). According to the theory of bounded generalized reciprocity (Yamagishi et al., 1999), people's prosocial behavior in social interactions in groups is influenced by their expectations of positive and reciprocal behaviors (i.e. generalized reciprocity) from other group members. When people expect others to behave positively and to reciprocate favors, it is in their self-interest to behave positively themselves and to reciprocate these 
favors to other group members. If they do not, they risk being perceived as a freeloader and this diminishes their likelihood to receive favors from anyone else in the group. The theory of bounded generalized reciprocity predicts that when people perceive a norm of generalized reciprocity, for example, by observing others behave prosocially or by being treated positively by others, they will behave prosocially themselves. In this way, reinforcing sequences of being the recipient and the actor of online prosocial behavior may develop. Applied to online contexts, this phenomenon can also manifest itself, especially in contexts in which group membership is salient, such as on social network sites and in group chat conversations. As group membership shapes reciprocal behavior and social media facilitate group communication (Lai and Turban, 2008), norms of reciprocal prosocial behavior may quickly develop in online social networks when people witness others behaving prosocially or are the recipient of prosocial behavior themselves and feel that it is expected of them to do the same. This process may even be more widespread online than offline, because online actions have the potential to reach a wider audience and to be witnessed long after they have actually taken place, compared to offline actions, which can only be witnessed by the people present at that particular place and time.

Alternatively, the reinforcing spirals model (Slater, 2007) proposes that media use affects individuals' attitudes and behavior, which in their turn influence subsequent media use through selection and attention processes, resulting in a spiral that is mutually reinforcing over time. Applying this theory to online social behavior, it predicts that adolescents' exposure to computer-mediated interactions influences their own cognitions and behaviors related to normative online behavior and shapes their subsequent computer-mediated interactions. Regarding online prosocial behavior, it could be that when adolescents experience social support and recognition from peers online, these experiences stimulate them to interact more frequently with those peers (selection effect) and reciprocate their behavior, resulting in a positive reinforcing cycle of prosocial interactions.

So far, a few studies (cited above) have provided indications for the existence of reciprocity online in specific contexts (online video game communities, freecycle communities, and couchsurfing.com); however, to the best of the authors' knowledge, no previous research has directly examined general online prosocial behavior in terms of associations between being a recipient and being an actor of that behavior. With general online prosocial behavior, we refer to online prosocial interactions between peers, such as comforting or complimenting others through online messages.

\section{Analysis of the dynamics of online social behavior}

So far, online antisocial and prosocial behaviors have mainly been studied independently, in different research disciplines and populations, and with differing methods. Online prosocial behavior has often been studied either with experimental research, by observing people's behavior in social exchange contexts (e.g. Stanca, 2009), or with questionnaires, interviews or focus groups, by asking participants what drives their actions online (e.g. Lauterbach et al., 2009).

With regard to online antisocial behavior, the cyberbullying-cybervictimization relationship has mainly been analyzed in cross-sectional studies, investigating the rates of 
individuals reporting to be involved both as perpetrator and as victim, or assessing correlations between cyberperpetration and cybervictimization. These types of analysis focus on inter-individual variation and yield between-subject or population-level associations (Molenaar and Campbell, 2009). Specifically, a positive cross-sectional correlation indicates that individuals who cyberbully others more than the group average are also more often than average victimized online. However, drawing inferences from patterns observed between persons to patterns within persons over time is not warranted (Kievit et al., 2013; Molenaar and Campbell, 2009). Cross-sectional population-level associations do not shed light on the causal and temporal directions of the association at the individual (or within-person) level (i.e. do cyberbullies become later cybervictims, or vice versa?). To examine within-individual associations and processes over time, longitudinal data are needed.

Traditional longitudinal methods: cross-lagged panel models. Fortunately, some cyberbullying studies have used longitudinal data to examine the cybervictimization-cyberperpetration association over time, and these could provide more insight into the sequence of behaviors. Several of these studies have used traditional cross-lagged panel structural equation models as method of analysis (Barlett and Gentile, 2012; Espelage et al., 2013; Pabian and Vandebosch, 2015; Van den Eijnden et al., 2014). Cross-lagged panel models (CLPMs) are often used to study the influence of two variables measured on more than one occasion on each other over time. In these models, each variable is regressed on its own previous score and on the other variable's previous score. This results in two types of regressions: autoregressive and cross-lagged. Autoregressive paths are believed to represent the stability of a variable over time. Cross-lagged paths are believed to represent the association between two variables over time (or the change in one variable related to the previous score on the other variable), controlling for the stability of the constructs involved. By comparing the relative strength of the (standardized) cross-lagged regression coefficients, researchers estimate which variable has the strongest causal influence.

With regard to cyberbullying, positive autoregressive relations for cyberperpetration and cybervictimization, interpreted as stability over time, have consistently been reported (Barlett and Gentile, 2012; Espelage et al., 2013; Pabian and Vandebosch, 2015; Van Den Eijnden et al., 2014). The findings for cross-lagged relations from cyberperpetration to cybervictimization and vice versa are mixed. One study among university students reported positive cross-lagged associations in both directions (Barlett and Gentile, 2012), two studies among middle school students found positive cross-lagged associations between cybervictimization and cyberperpetration but not the other way around (Barlett and Wright, 2017; Espelage et al., 2013), another study did not report significant cross-lagged associations (Pabian and Vandebosch, 2015), and a final study among adolescents found a negative association between cybervictimization and cyberperpetration (Van Den Eijnden et al., 2014), although the authors noted that this could be an artifact of their multivariate analysis.

With regard to online prosocial behavior, to the best of the authors' knowledge, so far CLPMs have not yet been used to study the long-term dynamics of this behavior.

Alternative longitudinal methods: random-intercept cross-lagged panel models. CLPM are attractive because they seem to provide insight into the causal processes between 
variables, accounting for their stability over time. However, these models have been criticized for not accounting for "the right type of stability" (Hamaker et al., 2015: 102). Hamaker et al. (2015) argue that autoregressive parameters fail to control for trait-like, time-invariant stability in the constructs. The autoregressive parameters in CLPM only account for temporal stability, not trait-like, time-invariant stability of constructs. In this way, it is not possible to separate within-person variability from between-person variability, and only between-person variability is estimated. This may result in invalid conclusions regarding the causal processes involved, as the CLPM-parameter estimates only reflect inter-individual, rather than intra-individual processes.

Applied to cyberbullying, using traditional CLPM assumes that there are no trait-like, time-invariant individual differences at play in cyberbullying involvement. This seems a questionable assumption, as research on bullying has shown stable individual differences in involvement in bullying. For instance, regarding victimization, some people are never bullied, whereas others are chronically victimized (Barker et al., 2008; Bowes et al., 2013; Smokowski et al., 2014). Moreover, victimization and perpetration can be predicted by (stable) personal and family features (Ang, 2015; Arseneault et al., 2010; Guo, 2016).

Similarly, prosocial behavior is associated with stable individual characteristics, such as intelligence and temperamental features (Veenstra, 2006), and shows consistent between-person differences (Eisenberg et al., 2002).

It is important to take those stable inter-individual differences into account in order to disentangle between-person effects (e.g. pooled across all people, are cybervictimization and cyberperpetration associated over time?) and within-person effects (e.g. does being victimized increase the likelihood of cyberbullying others over time and vice versa?). In this regard, Hamaker et al. (2015) have proposed an alternative to the traditional CLPM, called the random-intercept cross-lagged panel model (RI-CLPM), which includes a random intercept to account for invariant, trait-like stability in the involved constructs (i.e. between-person effects), in addition to temporal stability. The RI-CLPM takes into account the multilevel structure of longitudinal data, namely, that measurement occasions are nested within individuals and separates the within-person level from the between-person level. This model does make it possible to separately assess within-person and between-person variability over time and allows for more accurate estimates of within-person change and stability (Hamaker et al., 2015). The RI-CLPM has already been applied in studies on perceived social support and post-traumatic stress (Birkeland et al., 2016), parental monitoring and adolescent problem behavior (Keijsers, 2016), and health anxiety and online information-seeking (Te Poel et al., 2016) but to the best of our knowledge not to online antisocial or prosocial behavior.

\section{This study}

In this study, we aim to shed light on the within- and between-person dynamics of online antisocial and prosocial behavior among adolescents. We focus on cyberbullying as a proxy of online antisocial behavior, because the majority of research about online antisocial behavior has been conducted on cyberbullying, and previous studies on offline social behavior have also contrasted prosocial behavior with bullying (Menesini and Camodeca, 
2008; Warden and Mackinnon, 2003). Although a large body of research has explored the inter-individual processes, there remains a paucity of research on the intra-individual processes behind cyberbullying. Moreover, very little attention has been paid to adolescents' online prosocial behavior and the dynamics behind it.

Therefore, this study explores the dynamics behind adolescents' online social behavior by examining the associations between CBV and CBP on one hand and receiving and performing online prosocial behavior (ROPB and POPB, respectively) on the other hand, using RI-CLPMs. To this aim, we conducted a three-wave panel study among 12- to 14-year-old adolescents. This population was selected because research has shown that cyberbullying shows a peak during adolescence (Barlett and Coyne, 2014; Pabian and Vandebosch, 2016) and that significant developments in prosocial behavior take place during this life phase (Van Hoorn et al., 2016). Based on previous research findings and propositions of the GAM (Anderson and Bushman, 2002), the theory of bounded generalized reciprocity (Yamagishi et al., 1999), and the reinforcing spirals model (Slater, 2007), we propose the following hypotheses:

H1. Cyberbullying victimization (respectively, perpetration) increases subsequent cyberbullying perpetration (respectively, victimization).

H2. Receiving (respectively, performing) online prosocial behavior increases subsequent performing (respectively, receiving) of online prosocial behavior.

\section{Method}

\section{Procedure}

This study comprised three data collection waves separated by a 6-month time lag, administered between March 2015 and May 2016. To recruit participants, 30 randomly selected secondary education schools from one province in Belgium were asked to participate and 13 schools consented. In each school, all the students from the first year (equivalent to US grade 7) participated in the first wave, and all the students from the second year in the second and third wave (because a new school year started after the first wave). The school principals and the students provided active consent, and the students' parents provided passive consent. Of all the students who were asked to participate, 13 did not provide consent themselves or did not receive consent from their parents to participate. The Ethics Committee for the Social Sciences and Humanities of the University of Antwerp provided ethical approval for the study.

The participants completed a questionnaire in their classrooms during school hours, either on paper or electronically, in the presence of the first author and/or school personnel. In classes where the author was not present during administration, the school personnel was thoroughly informed about the survey procedures. Participants were encouraged to ask questions and to signal any items that were unclear during administration. They were informed that their data would be treated confidentially. To be able to link participants' data from the three waves, a few biographical questions were asked (e.g. the first letter of their mother's name), but these data were not coupled to their answers on the survey. 


\section{Participants}

The total number of participants was 2168 . In the first wave, 1721 students ( $45.7 \%$ boys) participated, 1746 (45.1\% boys) in the second wave, and 1590 (44.3\% boys) in the third wave. Practical issues in data collection led to the non-participation of four classes in the first wave, two classes in the second wave, and eight classes in the third wave. Participants' mean age was 13.01 years (standard deviation $[S D]=0.55$ ) in the first, 13.55 years $(S D=0.55)$ in the second, and 14.08 years $(S D=0.56)$ in the third wave. The majority of the participants were in general education, and $11-14 \%$ of participants in vocational education.

\section{Measures}

CBP and CBV. The European Cyberbullying Intervention Project Questionnaire (Brighi et al., 2012; Del Rey et al., 2015; Schultze-Krumbholz et al., 2015) was used as a measure of CBP and CBV. For each of 11 items (e.g. "Say mean things to someone or call someone names"), participants rated how often in the past month they had performed (for perpetration) or experienced (for victimization) each behavior on digital media on a 5-point Likert-type scale with ratings from 1 (never) to 5 (every day). The item "Post embarrassing videos or pictures of others online" was omitted because participants remarked that they perform this behavior for fun on Facebook for a friend's birthday. Mean scores were computed using the remaining 10 items (each) on CBP and CBV $\left(\mathrm{CBP}: M_{\mathrm{W} 1}=1.22, M_{\mathrm{W} 2}=1.22, M_{\mathrm{W} 3}=1.26 ; \mathrm{CBV}: M_{\mathrm{W} 1}=1.22, M_{\mathrm{W} 2}=1.21, M_{\mathrm{W} 3}=1.25\right)$. Cronbach's alpha values at waves 1,2 , and 3 were .71, .76, and .79 for CBP and .78, .80, and .82 for CBV.

POPB and ROPB. The Online Prosocial Behavior Scale (Erreygers et al., 2017) was used as a measure of receiving and performing online prosocial behavior. This scale was specifically developed to measure adolescents' online prosocial peer interactions, and it has been shown to be a valid and reliable instrument (authors, under review). Many items of the measures of online antisocial and prosocial behavior mirror each other (e.g. "say nice things to someone" vs "say mean things to someone" and "exclude someone from a group conversation" vs "include someone in a group conversation"), illustrating the link between these concepts. For each of 10 items (e.g. "Cheer someone up" and "Offer help to someone"), participants rated how often in the past month they had performed (POPB) or been recipient (ROPB) of each behavior using digital media on a 5-point Likert-type scale with ratings from 1 (never) to 5 (every day). Mean scores were computed for each subscale (POPB: $M_{\mathrm{W} 1}=3.33, M_{\mathrm{W} 2}=3.31, M_{\mathrm{W} 3}=3.32$; ROPB: $M_{\mathrm{W} 1}=2.99, M_{\mathrm{W} 2}=2.99$, $\left.M_{\mathrm{W} 3}=3.00\right)$. Cronbach's alpha values at all waves were $.90-.91$, for both subscales.

\section{Statistical analysis}

Structural equation modeling (SEM) was applied to analyze the associations between CBP and CBV, and between POPB and ROPB, using Mplus 7.4 (Muthén and Muthén, 2015). Two RI-CLPMs (Hamaker et al., 2015) were modeled to examine the directional 
effects in cyberbullying and online prosocial behavior, following the approach outlined by Hamaker et al. (2015). First, in each model one random intercept was created for $\mathrm{CBP}, \mathrm{CBV}$, POPB, and ROPB each, by regressing their observed composite (mean) scores of the three waves on one latent factor and constraining the factor loadings to one. These random intercepts reflect the invariant, trait-like interpersonal differences in the variables, and in this way, the between-person variability can be separated from the within-person variability. Second, latent variables of the observed scores were created by regressing these scores on latent factors while constraining the factor loadings to one and constraining the variances of the observed variables to zero. These latent factors take into account the within- and between-person variability. The covariances between the random intercepts and the latent variables of the observed scores were constrained to zero, as well as the means of the observed variables. Because the intervals between the waves were equally spaced, the lagged parameters were constrained to be equal across waves. ${ }^{3}$ To take the non-normality of the data into account, maximum likelihood estimation with robust standard errors (MLR) was used. Full information maximum likelihood (FIML) estimation with robust standard errors was applied to handle missing data.

\section{Results}

First, the intra-class correlation coefficients for each construct were calculated in SPSS 23 to examine the proportion of the variance accounted for by between- and withinindividual differences. These were .526 for POAB, .486 for ROAB, and .611 for both POPB and ROPB, meaning that $49-61 \%$ of the variance in these variables over time was due to inter-individual differences, whereas $39-51 \%$ of the variance was due to variability (or fluctuations) within individuals. Traditional CLPM-models do not take into account these stable inter-individual differences; therefore, we applied RI-CLPM in which the random intercepts account for the stable inter-individual variability (see Figure 1 for the model for cyberbullying; an equivalent model was used for online prosocial behavior).

\section{Cyberbullying}

The RI-CLPM showed an excellent fit for the associations between CBP and CBV, $\chi^{2}(9)=15.131(p=.088)$, root mean square error of approximation (RMSEA) $=.018(90 \%$ confidence interval $[\mathrm{CI}]=[.000, .033])$, comparative fit index $(\mathrm{CFI})=.994$, TuckerLewis Index $(\mathrm{TLI})=0.989$, and standardized root mean square residual $(\mathrm{SRMR})=.026$. The parameter estimates (see Table 1) indicate that stable between-person differences in cyberperpetration are positively associated with stable between-person differences in cybervictimization. This means that, across waves, adolescents who reported to be more often than average engaged in CBP also reported to be victims of cyberbullying more often. Furthermore, the significant wave 1-covariation and wave 2 and 3-residual covariations indicate that within-person change (or deviation from an individual's expected score) in CBP and within-person change (or deviation from an individual's expected score) in CBV are also associated. Hence, adolescents who reported increasing CBP at a 


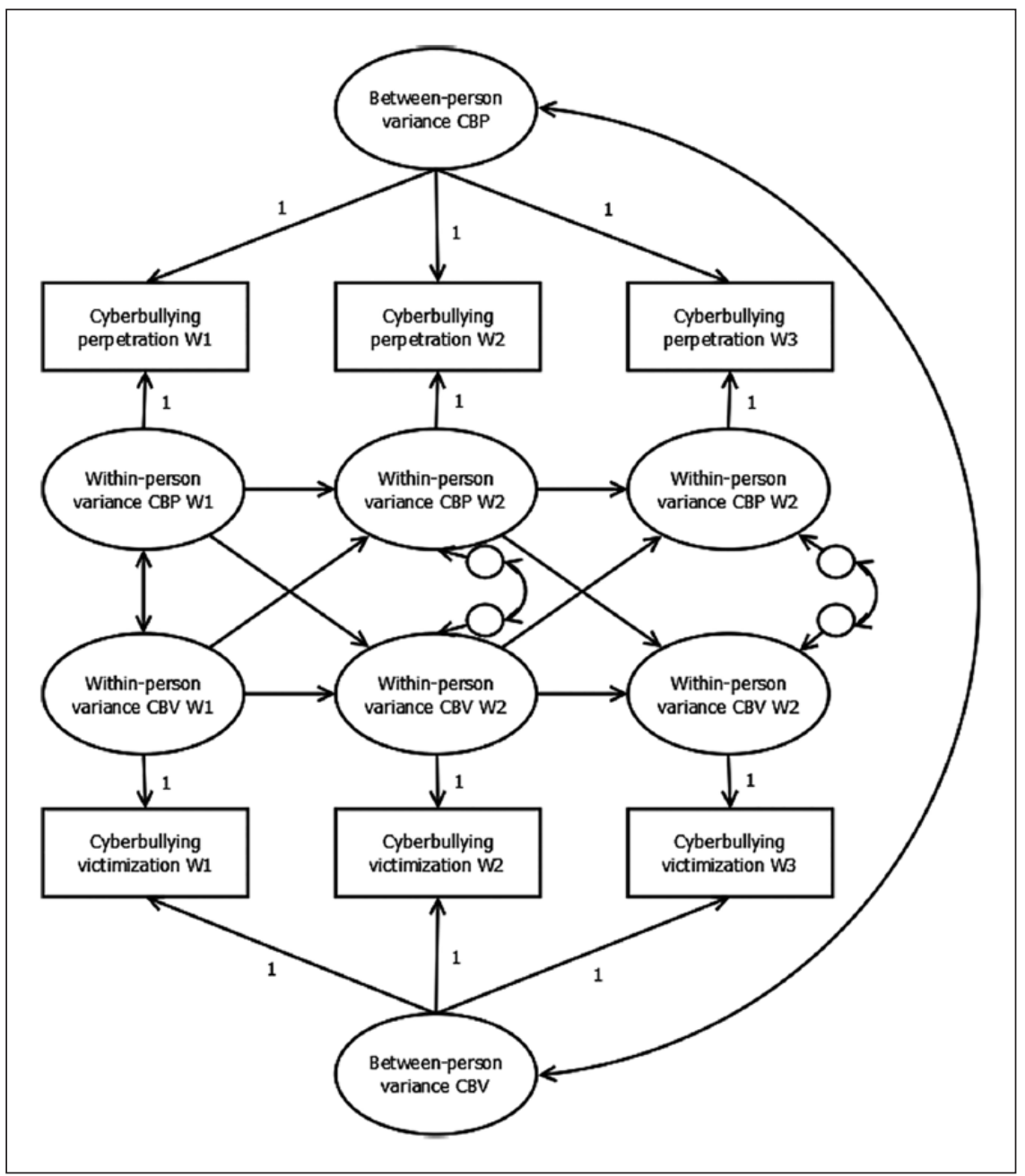

Figure I. Random intercept cross-lagged panel model (RI-CLPM) for the association between cyberbullying perpetration (CBP) and cyberbullying victimization (CBV) across three waves. The two random intercepts ("between-person variance CBP" and "between-person variance CBV") represent stable inter-individual differences. The autoregressive and cross-lagged paths between the latent factors, the correlation between the latent factors at wave I, and the correlated residuals at wave 2 and 3 represent within-person processes.

particular point in time also reported more $\mathrm{CBV}$ at that time point. This association is not linked to changes in cyberbullying involvement 6 months earlier but is attributable to an (unknown) time-varying process. Most strikingly, by explicitly modeling the inter-individual differences in cyberbullying, no significant autoregressive or cross-lagged paths emerge. This means that over time there are no within-person influences of adolescents' $\mathrm{CBP}$ on their later perpetration or victimization and vice versa. 
Table I. Unstandardized (B) and standardized $(\beta)$ parameter estimates of the random intercept cross-lagged panel model (RI-CLPM) for the longitudinal associations between cyberbullying perpetration and victimization, and between performing and receiving of online prosocial behavior, across three waves.

\begin{tabular}{llllll}
\hline & $B$ & $S E(B)$ & $\beta$ & $S E(\beta)$ & $P(\beta)$ \\
\hline Cyberbullying & & & & & \\
Perpetration WI $\rightarrow$ Perpetration W2 & 0.118 & 0.110 & 0.108 & 0.098 & .270 \\
Perpetration W2 $\rightarrow$ Perpetration W3 & 0.118 & 0.110 & 0.090 & 0.088 & .306 \\
Victimization WI $\rightarrow$ Victimization W2 & 0.125 & 0.090 & 0.128 & 0.092 & .163 \\
Victimization W2 $\rightarrow$ Victimization W3 & 0.125 & 0.090 & 0.103 & 0.077 & .182 \\
Perpetration WI $\rightarrow$ Victimization W2 & 0.105 & 0.095 & 0.086 & 0.078 & .274 \\
Perpetration W2 $\rightarrow$ Victimization W3 & 0.105 & 0.095 & 0.077 & 0.074 & .296 \\
Victimization WI $\rightarrow$ Perpetration W2 & 0.056 & 0.065 & 0.065 & 0.073 & .371 \\
Victimization W2 $\rightarrow$ Perpetration W3 & 0.056 & 0.065 & 0.049 & 0.058 & .400 \\
Covariation WI & 0.012 & 0.005 & 0.229 & 0.076 & .003 \\
Residual covariation W2 & 0.024 & 0.008 & 0.434 & 0.084 & .000 \\
Residual covariation W3 & 0.046 & 0.007 & 0.510 & 0.049 & .000 \\
Between-person covariation & 0.045 & 0.007 & 0.758 & 0.051 & .000 \\
Online prosocial behavior & & & & & \\
Performing WI $\rightarrow$ Performing W2 & 0.143 & 0.071 & 0.150 & 0.072 & .038 \\
Performing W2 $\rightarrow$ Performing W3 & 0.143 & 0.071 & 0.152 & 0.076 & .047 \\
Receiving WI $\rightarrow$ Receiving W2 & 0.124 & 0.061 & 0.137 & 0.066 & .038 \\
Receiving W2 $\rightarrow$ Receiving W3 & 0.124 & 0.061 & 0.133 & 0.067 & .046 \\
Performing WI $\rightarrow$ Receiving W2 & 0.129 & 0.069 & 0.126 & 0.068 & .065 \\
Performing W2 $\rightarrow$ Receiving W3 & 0.129 & 0.069 & 0.129 & 0.072 & .072 \\
Receiving WI $\rightarrow$ Performing W2 & 0.116 & 0.048 & 0.137 & 0.056 & .015 \\
Receiving W2 $\rightarrow$ Performing W3 & 0.116 & 0.048 & 0.132 & 0.057 & .020 \\
Covariation WI & 0.273 & 0.025 & 0.726 & 0.024 & .000 \\
Residual covariation W2 & 0.222 & 0.023 & 0.732 & 0.027 & .000 \\
Residual covariation W3 & 0.180 & 0.017 & 0.672 & 0.027 & .000 \\
Between-person covariation & 0.310 & 0.027 & 0.894 & 0.015 & .000 \\
\hline
\end{tabular}

SE: standard error.

\section{Online prosocial behavior}

The RI-CLPM for online prosocial behavior also showed an excellent fit, $\chi^{2}(9)=2.821$ $(p=.971), \quad$ RMSEA $=.000 \quad(90 \% \mathrm{CI}=[.000, .000]), \mathrm{CFI}=1.000, \mathrm{TLI}=1.002$, and $\mathrm{SRMR}=.006$. The parameter estimates (see Table 1 ) indicate that performing and receiving online prosocial behavior are significantly correlated, both at the stable, betweenperson level, as at the time-varying within-person level. In other words, adolescents who reported to behave more prosocially than average online also reported to be recipients of prosocial behavior performed by others more often. Furthermore, the autoregressive paths of POPB and ROPB are significant, indicating that within-person deviations from expected scores on POPB predict later deviations from expected scores on POPB, and likewise for ROPB. In other words, within persons, an increase in performing (or 
receiving) online prosocial behavior leads to even more performing (or receiving) of prosocial behavior later on. Finally, the cross-lagged paths from ROPB to POPB are significant, reflecting that deviations from adolescents' own expected score on ROPB are predicted by deviations from their own expected score on POPB 6 months earlier. Stated differently, receiving more online prosocial behavior leads to increases in prosocial acting online later on.

\section{Discussion}

This study aimed to provide insight into the within- and between-person processes behind the associations between the performing and receiving of online antisocial and prosocial behavior. Applying RI-CLPMs in a sample of 2168 adolescents, the longitudinal associations between perpetration and victimization of cyberbullying on one hand and performing and receiving online prosocial behavior on the other hand were tested across three waves of data collection spaced 6 months apart.

The results suggest that $\mathrm{CBV}$ and $\mathrm{CBP}$ are positively associated at the stable betweenperson level and covary in the same direction over time, but within individuals, involvement in cyberbullying at one time point does not predict later CBV or CBP. Stated differently, we did not find evidence for a long-term pattern in which individuals who are cyberbullied later cyberbully others and vice versa. Thus, the current findings do not indicate the presence of long-term negative spirals of online antisocial behavior, specifically cyberbullying. Our findings do not support an over-time escalating cycle of cyberbullying others and being cyberbullied oneself.

Our findings on the absence of bidirectional relationships between cybervictimization and cyberperpetration contrast with predictions from the GAM (Anderson and Bushman, 2002) and with some of the previous findings on the longitudinal associations in cyberbullying (Barlett and Gentile, 2012; Espelage et al., 2013; Pabian and Vandebosch, 2015; Van Den Eijnden et al., 2014). However, this study is the first to use RI-CLPM, a method that allows to disentangle between-person effects from within-person effects in the link between cybervictimization and cyberperpetration. Our results do confirm the previously reported association between cybervictimization and cyberperpetration when examined at a between-person level of analysis: Adolescents who are more frequently victimized online also cyberbully others more often. In addition, within-person deviations in CBV are also linked to within-person deviations in CBP (the variables covary across time). Thus, CBP and CBV rates vary synchronously both between and within individuals.

Between-person differences in variables which have been identified as risk factors for cyberbullying, such as family or personal characteristics (Ang, 2015; Guo, 2016; Kowalski et al., 2014), may play a role in this association, especially because research has shown that there is a significant overlap in the antecedents of $\mathrm{CBV}$ and $\mathrm{CBP}$ (Kowalski et al., 2014). The findings are also consistent with those of previous studies using person-centered clustering techniques (latent class or transition analysis) to examine involvement in cyberbullying, which have shown that for most adolescents cyberbullying involvement most often entails co-occurring victimization and perpetration, and not exclusive victimization or perpetration (Festl et al., 2017; Schultze-Krumbholz et al., 
2015). Furthermore, factor analyses of cyberbullying instruments have shown that many items measuring CBP and CBV load on one single "cyberbullying victimization/perpetration" factor (Law et al., 2012; Menesini et al., 2011). In sum, our findings confirm the link between CBV and CBP but do not provide support for a long-term dynamic process in which being cyberbullied leads to cyberbullying others 6 months later and vice versa.

In contrast, the association between being the beneficiary of online prosocial behavior and behaving prosocially online does reflect within-person reinforcements of this behavior over time. In other words, the findings reveal positive spirals of online prosocial behavior within adolescents, such that (1) those who behave more prosocially online will increase this behavior over time, (2) those who benefit more from others' online prosocial behavior toward them will increasingly benefit over time, and (3) will increasingly act prosocially toward others themselves. (The findings also provide some indications that more often performing online prosocial behavior leads to later increases in receiving this behavior, but these results are only significant at $p<.10$.) These findings are consistent with the theory of bounded generalized reciprocity (Yamagishi et al., 1999) in online contexts, which posits that when people observe others behaving prosocially, this creates an expectation of reciprocal prosocial behavior and motivates them to behave prosocially themselves.

It might be that cycles of negative behavior online occur more rapidly than cycles of positive behavior. Perhaps the sequences of CBV and CBP happen on a short term or almost simultaneously, for example, immediately bullying back after having been bullied, whereas the sequences of prosocial exchanges take more time or last longer. Nevertheless, the results of our study suggest that being the recipient of online prosocial behavior has long-lasting increasing effects on acting prosocially online, whereas this is not evident for online antisocial behavior.

Another possible explanation for the existence of a positive spiral but the lack of a negative spiral may be found in the emotions linked to these behaviors. When individuals are the beneficiary of others' prosocial behavior, they are likely to experience positive emotions, such as gratitude and happiness, and these may stimulate them to act prosocially toward others themselves (Bartlett and De Steno, 2006). In contrast, when people are the target of others' negative actions, this may elicit negative emotions which prepare approach (e.g. anger stimulates revenge) or avoidance (e.g. fear and sadness stimulate withdrawal) action tendencies (Frijda, 1986), that is, stimulate or inhibit reactions against the other. However, due to the possibility for anonymity online it may not always be clear who the perpetrator is, hence, reacting against the perpetrator is not always possible. Furthermore, victims may be less technologically skilled (Vandebosch and Van Cleemput, 2008 ) or the costs of retaliation may outweigh the benefits (cf. social exchange theory, Emerson, 1976), making retaliation less likely. An alternative explanation may be derived from the reinforcing spirals model (Slater, 2007), which posits that media use influences individuals' cognitions and behavior, which shapes their subsequent media use. On one hand, when adolescents are exposed to online peer social support and recognition, this may motivate them to interact more frequently with those peers and imitate their behavior, resulting in a positive reinforcing cycle of prosocial interactions. In contrast, when adolescents are exposed to antisocial online behavior, they often turn to others for help to stop the harassment or avoid further contact with the offender, for example, by 
unfriending or blocking (Šléglová and Černá, 2011; Weinstein et al., 2016). Consequently, the exposure to that behavior may decrease, and reinforcing spirals do not develop.

As our study sample was limited to young adolescents, caution should be applied when generalizing these results to other populations. Furthermore, the data were solely based on participants' self-reports. These may have been subject to social desirability bias, leading to underreporting of cyberbullying involvement or overreporting of prosocial behavior. Future studies could benefit from including other-reports to obtain a view of how others perceive the participants' behavior. Notwithstanding these limitations, the findings of this study provide a better understanding of the processes at play in adolescents' online antisocial and prosocial interactions. Our results suggest a long-term mutual reinforcement of being the recipient and actor of online prosocial behavior, whereas no evidence was found for a within-person longitudinal bidirectional relationship between being a cyberbully and being a cybervictim. In conclusion, this study shows that online prosocial behavior engenders long-term positive spirals of prosocial exchanges, but cyberbullying does not result in long-term negative spirals of antisocial interactions.

\section{Declaration of Conflicting Interests}

The author(s) declared no potential conflicts of interest with respect to the research, authorship, and/or publication of this article.

\section{Funding}

The author(s) disclosed receipt of the following financial support for the research, authorship, and/ or publication of this article: This work was supported by the Research Foundation Flanders, Grant FWO G.0335.14N.

\section{ORCID iD}

Sara Erreygers (iD https://orcid.org/0000-0002-3097-4784

\section{Notes}

1. Although cyberbullying is a type of online antisocial behavior, it can be studied on the same level as online prosocial behavior. Cyberbullying as a concept also encompasses several types of behavior (Pieschl et al., 2013). Furthermore, research with 9- to 13-year-old children has shown that when asked to describe antisocial incidents, they describe four categories of antisocial behavior, such as physical abuse, verbal abuse, rejection, and delinquency (Warden and Christie, 1997; Warden et al., 1996). These categories correspond to behavior categories typically identified in (traditional) bullying research (Whitney and Smith, 1993).

2. The term reciprocity is also sometimes used in the context of negative or antisocial behavior, referring to the norms and beliefs that people have toward retribution and revenge as a valid response against unfavorable treatment. Here, we use the term reciprocity to refer to positive reciprocity only.

3. We also tested the models without constraints on the lagged parameters, but these did not have a better fit than the constrained models. Cyberbullying: $\chi^{2}(5)=19.152(p=.971)$, root mean square error of approximation $(\mathrm{RMSEA})=.036(90 \%$ confidence interval $[\mathrm{CI}]=[.020, .054])$, comparative fit index $(\mathrm{CFI})=.985$, Tucker-Lewis Index $(\mathrm{TLI})=0.956$, and standardized root mean square residual $(\mathrm{SRMR})=.022$; online prosocial behavior: $\chi^{2}(5)=2.953(p=.707)$, $\mathrm{RMSEA}=.000(90 \% \mathrm{CI}=[.000, .022]), \mathrm{CFI}=1.000, \mathrm{TLI}=1.001$, and $\mathrm{SRMR}=.004$. 


\section{References}

Ak Ş, Özdemir Y and Kuzucu Y (2015) Cybervictimization and cyberbullying: the mediating role of anger, don't anger me! Computers in Human Behavior 49: 437-443.

Allen JJ, Anderson CA and Bushman BJ (2018) The general aggression model. Current Opinion in Psychology 19: 75-80.

Anderson CA and Bushman BJ (2002) Human aggression. Annual Review of Psychology 53(1): 27-51.

Anderson CA, Buckley KE and Carnagey NL (2008) Creating your own hostile environment: a laboratory examination of trait aggressiveness and the violence escalation cycle. Personality and Social Psychology Bulletin 34(4): 462-473.

Ang RP (2015) Adolescent cyberbullying: a review of characteristics, prevention and intervention strategies. Aggression and Violent Behavior 25(A): 35-42.

Arseneault L, Bowes L and Shakoor S (2010) Bullying victimization in youths and mental health problems: "much ado about nothing"? Psychological Medicine 40: 717-729.

Barker ED, Arseneault L, Brendgen M, et al. (2008) Joint development of bullying and victimization in adolescence: relations to delinquency and self-harm. Journal of the American Academy of Child and Adolescent Psychiatry 47(9): 1030-1038.

Barlett CP and Coyne SM (2014) A meta-analysis of sex differences in cyber-bullying behavior: the moderating role of age. Aggressive Behavior 40(5): 474-488.

Barlett CP and Gentile DA (2012) Attacking others online: the formation of cyberbullying in late adolescence. Psychology of Popular Media Culture 1(2): 123-135.

Barlett CP and Wright MF (2017) Longitudinal relations among cyber, physical, and relational bullying and victimization: comparing majority and minority ethnic youth. Journal of Child \& Adolescent Trauma. Epub ahead of print 25 July. DOI: 10.1007/s40653-0170174-8.

Bartlett MY and De Steno D (2006) Gratitude and prosocial behavior: helping when it costs you. Psychological Science 17(4): 319-325.

Bayraktar F, Machackova H, Dedkova L, et al. (2014) Cyberbullying: the discriminant factors among cyberbullies, cybervictims, and cyberbully-victims in a Czech adolescent sample. Journal of Interpersonal Violence 30: 3192-3216.

Birkeland MS, Knatten CK, Hansen MB, et al. (2016) Long-term relationships between perceived social support and posttraumatic stress after the 2011 Oslo bombing: a three-year longitudinal study. Journal of Affective Disorders 202: 230-235.

Bowes L, Maughan B, Ball H, et al. (2013) Chronic bullying victimization across school transitions: the role of genetic and environmental influences. Development and Psychopathology 25(2): 333-346.

Brighi A, Ortega R, Pyzalski J, et al. (2012) European Cyberbullying Intervention Project Questionnaire (ECIPQ). Unpublished manuscript, University of Bologna.

Del Rey R, Casas JA, Ortega-Ruiz R, et al. (2015) Structural validation and cross-cultural robustness of the European Cyberbullying Intervention Project Questionnaire. Computers in Human Behavior 50: 141-147.

Dovidio JF, Piliavin JA, Schroeder DA, et al. (2006) The Social Psychology of Prosocial Behavior. Mahwah, NJ: Lawrence Erlbaum.

Erreygers S, Vandebosch H, Vranjes I, et al. (2017) Development of a measure of adolescents' online prosocial behavior. Manuscript submitted for publication.

Eisenberg N, Fabes RA and Spinrad TL (2006) Prosocial development. In: Eisenberg N, Damon W and Lerner RM (eds) Handbook of Child Psychology. Social, Emotional, and Personality Development. 6th ed. New York: Wiley, pp. 646-718.

Eisenberg N, Guthrie IK, Cumberland A, et al. (2002) Prosocial development in early adulthood: a longitudinal study. Journal of Personality and Social Psychology 82(6): 993-1006. 
Emerson RM (1976) Social exchange theory. Annual Review of Sociology 2: 335-362.

Espelage DL, Rao MA and Craven RG (2013) Theories of cyberbullying. In: Bauman S, Cross $\mathrm{D}$ and Walker J (eds) Principles of Cyberbullying Research: Definitions, Measures, and Methodology. New York: Routledge, pp. 49-67.

Ewoldsen DR, Eno CA, Okdie BM, et al. (2012) Effect of playing violent video games cooperatively or competitively on subsequent cooperative behavior. Cyberpsychology, Behavior, and Social Networking 15(5): 277-280.

Festl R and Quandt T (2016) The role of online communication in long-term cyberbullying involvement among girls and boys. Journal of Youth and Adolescence 45(9): 1931-1945.

Festl R, Scharkow M and Quandt T (2015) The individual or the group: a multilevel analysis of cyberbullying in school classes. Human Communication Research 41(4): 535-556.

Festl R, Vogelgesang J, Scharkow M, et al. (2017) Longitudinal patterns of involvement in cyberbullying: results from a Latent Transition Analysis. Computers in Human Behavior 66: 7-15.

Frijda NH (1986) The Emotions. Cambridge: Cambridge University Press.

Gray K, Ward AF and Norton MI (2014) Paying it forward: generalized reciprocity and the limits of generosity. Journal of Experimental Psychology: General 143(1): 247-254.

Greitemeyer T and Cox C (2013) There's no "I" in team: effects of cooperative video games on cooperative behavior. European Journal of Social Psychology 43(3): 224-228.

Guo S (2016) A meta-analysis of the predictors of cyberbullying perpetration and victimization. Psychology in the Schools 53(4): 432-453.

Hamaker EL, Kuiper RM and Grasman RPPP (2015) A critique of the cross-lagged panel model. Psychological Methods 20(1): 102-116.

Keijsers L (2016) Parental monitoring and adolescent problem behaviors: how much do we really know? International Journal of Behavioral Development 40(3): 271-281.

Keysar B, Converse Ba, Wang J, et al. (2008) Reciprocity is not give and take: asymmetric reciprocity to positive and negative acts. Psychological Science 19(12): 1280-1286.

Kievit RA, Frankenhuis WE, Waldorp LJ, et al. (2013) Simpson's paradox in psychological science: a practical guide. Frontiers in Psychology 4(513): 1-14.

König A, Gollwitzer M and Steffgen G (2010) Cyberbullying as an act of revenge? Australian Journal of Guidance and Counselling 20(2): 210-224.

Kowalski RM, Giumetti GW, Schroeder AN, et al. (2014) Bullying in the digital age: a critical review and meta-analysis of cyberbullying research among youth. Psychological Bulletin 140(4): 1073-1137.

Kowalski RM, Limber SP and Agatston PW (2012) Cyberbullying: Bullying in the Digital Age. 2nd ed. Chichester: Wiley-Blackwell.

Lai LSL and Turban E (2008) Groups formation and operations in the Web 2.0 environment and social networks. Group Decision and Negotiation 17(5): 387-402.

Lauterbach D, Truong H, Shah T, et al. (2009) Surfing a web of trust: reputation and reciprocity on couchsurfing.com. In: Proceedings of the 2009 international conference on computational science and engineering, Vancouver, BC, Canada, 29-31 August, pp. 346-353. New York: IEEE.

Law DM, Shapka JD, Hymel S, et al. (2012) The changing face of bullying: an empirical comparison between traditional and internet bullying and victimization. Computers in Human Behavior 28(1): 226-232.

McLure Wasko M and Faraj S (2000) "It is what one does": why people participate and help others in electronic communities of practice. The Journal of Strategic Information Systems 9(2-3): 155-173.

Menesini E and Camodeca M (2008) Shame and guilt as behaviour regulators: relationships with bullying, victimization and prosocial behaviour. British Journal of Developmental Psychology 26(2): 183-196.

Menesini E, Nocentini A and Calussi P (2011) The measurement of cyberbullying: dimensional structure and relative item severity and discrimination. Cyberpsychology, Behavior, and Social Networking 14(5): 267-274. 
Molenaar PCM and Campbell CG (2009) The new person-specific paradigm in psychology. Current Directions in Psychological Science 18(2): 112-117.

Muthén LK and Muthén BO (2015) Mplus User's Guide. 7th ed. Los Angeles, CA: Muthén \& Muthén.

Nelson MR and Rademacher MA (2009) From trash to treasure: freecycle.org as a case of generalized reciprocity. Advances in Consumer Research 36: 905-906.

Pabian S and Vandebosch H (2015) Short-term longitudinal relationships between adolescents' (cyber)bullying perpetration and bonding to school and teachers. International Journal of Behavioral Development 40: 165-172.

Pabian S and Vandebosch H (2016) Developmental trajectories of (cyber)bullying perpetration and social intelligence during early adolescence. The Journal of Early Adolescence 36(2): 145-170.

Pieschl S, Porsch T, Kahl T, et al. (2013) Relevant dimensions of cyberbullying - Results from two experimental studies. Journal of Applied Developmental Psychology. 34(5): 241-252.

Rankin DJ and Taborsky M (2009) Assortment and the evolution of generalized reciprocity. Evolution 63(7): 1913-1922.

Roberts G (2008) Evolution of direct and indirect reciprocity. Proceedings of the Royal Society B: Biological Sciences 275(1631): 173-179.

Schultze-Krumbholz A, Göbel K, Scheithauer H, et al. (2015) A comparison of classification approaches for cyberbullying and traditional bullying using data from six European countries. Journal of School Violence 14(1): 47-65.

Slater MD (2007) Reinforcing spirals: the mutual influence of media selectivity and media effects and their impact on individual behavior and social identity. Communication Theory 17(3): 281-303.

Šléglová V and Černá A (2011) Cyberbullying in adolescent victims: Perception and coping. Cyberpsychology: Journal of Psychosocial Research on Cyberspace 5(2).

Smith PK, Mahdavi J, Carvalho M, et al. (2008) Cyberbullying: its nature and impact in secondary school pupils. Journal of Child Psychology and Psychiatry and Allied Disciplines 49(4): 376-385.

Smokowski PR, Evans CBR and Cotter KL (2014) The differential impacts of episodic, chronic, and cumulative physical bullying and cyberbullying: the effects of victimization on the school experiences, social support, and mental health of rural adolescents. Violence and Victims 29(6): 1029-1046.

Sourander A, Brunstein Klomek A, Ikonen M, et al. (2010) Psychosocial risk factors associated with cyberbullying among adolescents: a population-based study. Archives of General Psychiatry 67(7): 720-728.

Stanca L (2009) Measuring indirect reciprocity: whose back do we scratch? Journal of Economic Psychology 30(2): 190-202.

Suler J (2004) The online disinhibition effect. Cyberpsychology \& Behavior 7(3): 321-326.

Te Poel F, Baumgartner SE, Hartmann T, et al. (2016) The curious case of cyberchondria: A longitudinal study on the reciprocal relationship between health anxiety and online health information seeking. Journal of Anxiety Disorders 43: 32-40.

Trivers RL (1971) The evolution of reciprocal altruism. The Quarterly Review of Biology 46(1): $35-57$.

Van Den Eijnden R, Vermulst A, Van Rooij AJ, et al. (2014) The bidirectional relationships between online victimization and psychosocial problems in adolescents: a comparison with real-life victimization. Journal of Youth and Adolescence 43(5): 790-802.

Van Hoorn J, Van Dijk E, Meuwese R, et al. (2016) Peer influence on prosocial behavior in adolescence. Journal of Research on Adolescence 26(1): 90-100. 
Van Rijsewijk L, Dijkstra JK, Pattiselanno K, et al. (2016) Who helps whom? Investigating the development of adolescent prosocial relationships. Developmental Psychology 52(6): 894-908.

Vandebosch H and Van Cleemput K (2008) Defining cyberbullying: a qualitative research into the perceptions of youngsters. Cyberpsychology \& Behavior 11(4): 499-503.

Vandebosch H and Van Cleemput K (2009) Cyberbullying among youngsters: profiles of bullies and victims. New Media \& Society 11(8): 1349-1371.

Veenstra R (2006) The development of Dr. Jekyll and Mr. Hyde: prosocial and antisocial behavior in adolescence. In: Fetchenhauer D, Flache A, Buunk AP, et al. (eds) Solidarity and Prosocial Behavior: An Integration of Sociological and Psychological Perspectives. Berlin: Springer, pp. 93-108.

Velez JA, Mahood C, Ewoldsen DR, et al. (2014) Ingroup versus outgroup conflict in the context of violent video game play. Communication Research 41(5): 607-626.

Völlink T, Bolman CAW, Dehue F, et al. (2013) Coping with cyberbullying: differences between victims, bully-victims and children not involved in bullying. Journal of Community \& Applied Social Psychology 23(1): 7-24.

Walrave M and Heirman W (2011) Cyberbullying: predicting victimisation and perpetration. Children \& Society 25(1): 59-72.

Warden D, Christie D, Kerr C, et al. (1996) Children's prosocial and antisocial behaviour, as perceived by children, parents and teachers. Educational Psychology 16(4): 365-378.

Warden D and Christie D (1997) Teaching social behaviour. London: David Fulton.

Warden D and Mackinnon S (2003) Prosocial children, bullies and victims: an investigation of their sociometric status, empathy and social problem-solving strategies. British Journal of Developmental Psychology 21(3): 367-385.

Weinstein EC, Selman RL, Thomas S, et al. (2016) How to cope with digital stress: The recommendations adolescents offer their peers online. Journal of Adolescent Research 31(4): $415-441$.

Whitney I and Smith PK (1993) A survey of the nature and extent of bullying in junior/middle and secondary schools. Educational Research 35(1): 3-25.

Wright MF and Li Y (2013) The association between cyber victimization and subsequent cyber aggression: the moderating effect of peer rejection. Journal of Youth and Adolescence 42(5): 662-674.

Yamagishi T, Jin N and Kiyonari T (1999) Bounded generalized reciprocity: ingroup boasting and ingroup favoritism. Advances in Group Processes 16: 161-197.

\section{Author biographies}

Sara Erreygers is a PhD candidate in communication sciences and psychology, who studies emotional processes underlying online social behavior such as cyberbullying. She is a member of the research units MIOS at the University of Antwerp and Occupational \& Organizational Psychology and Professional Learning (O2L) at the KU Leuven.

Heidi Vandebosch is a professor at the Department of Communication Sciences of the University of Antwerp (Belgium). Her research focuses on cyberbullying amongst children and adolescents (prevalence, profiles of bullies and victims, impact, ...) and the development of evidence-based ICT-interventions (i.e. serious games, reflective interfaces, ...).

Ivana Vranjes works on obtaining a $\mathrm{PhD}$ in Work and Organisational Psychology and Communication Sciences. She is a member of the research unit Occupational \& Organizational Psychology and Professional Learning (O2L) at the KU Leuven and the research unit MIOS at the 
University of Antwerp. Research interests: workplace (cyber) bullying, emotions, emotion regulation, technostress.

Elfi Baillien ( $\mathrm{PhD}$ in Psychology) is an associate professor at the Research Center for Work and Organisation Studies (WOS) of KU Leuven (Belgium), and at the Department of Pyschosocial Sience of the University of Bergen (Norway). Her research topics include workplace bullying, counterproductive work behaviour, interpersonal conflict, work stress, and employee well-being.

Hans De Witte (PhD in Psychology) is a full professor Work Psychology, and member of the research unit Occupational \& Organizational Psychology and Professional Learning (O2L) at the KU Leuven. He is also appointed at the Optentia Research Focus Area, NWU, South Africa. Research interests: psychological consequences of job insecurity, unemployment, temporary employment and downsizing; mobbing, burnout and work engagement. 